\title{
El Aprendizaje Cooperativo y las Habilidades Socio- Emocionales: Una Experiencia Docente en la Asignatura Técnicas de Ventas
}

\author{
Marta Estrada, Diego Monferrer y Miguel A. Moliner \\ Departamento de Administración de Empresas y Marketing. Universitat Jaume I. Castellón, España \\ (e-mail: estrada@emp.uji.es; dmonferr@emp.uji.es; amoliner@emp.uji.es)
}

Recibido Mar. 23, 2016; Aceptado May. 23, 2016; Versión final Jun. 22, 2016, Publicado Dic. 2016

\begin{abstract}
Resumen
En este trabajo se describe una experiencia docente llevada a cabo con 121 estudiantes de la asignatura Técnicas de Ventas del Grado en Administración de Empresas (Universitat Jaume I, Castellón, España) en la que, utilizando el aprendizaje cooperativo, se desarrollan las habilidades socio-emocionales y cognitivas necesarias para los futuros profesionales de la venta. La metodología planteada sigue un programa de acciones estructuradas secuencialmente en cinco fases (incluyendo técnicas de formación de equipos, talleres, actividades y casos docentes). Además se implementa un trabajo de campo para el análisis descriptivo de los datos y la aplicación de tests correlacionales. Los resultados obtenidos tras la experiencia muestran altos niveles en cada una de las habilidades que componen la inteligencia emocional del estudiante, así como un alto grado de satisfacción con respecto al proceso de aprendizaje cooperativo llevado a cabo.
\end{abstract}

\section{Cooperative Learning and Socio-Emotional Skills: A Teaching Experience in Sales Techniques Course}

\begin{abstract}
This work describes a teaching experience carried out with 121 students of the Sales Techniques course of the Bachelor's Degree in Business Administration (Universitat Jaume I Castellón, España), where socioemotional and cognitive skills needed by future sales professionals are developed by applying cooperative learning. The proposed methodology follows a program of actions sequentially structured in five stages (including team-building techniques, workshops, activities and teaching cases). Moreover field work was done for the descriptive analysis of the data and the application of correlational tests. The results obtained after the implementation of the experience show high levels in each of the skills that make up the emotional intelligence of students as well as a high degree of satisfaction with the cooperative learning process carried out.
\end{abstract}

Keywords: cooperative learning; emotional intelligence; sales; educational innovation 


\section{INTRODUCCIÓN}

Uno de los objetivos de la enseñanza-aprendizaje es formar personas capaces de interpretar los fenómenos y acontecimientos ocurridos en el entorno, ciudadanos preparados para contribuir al desarrollo de sociedades saludables y eficientes. El logro de esta meta se encuentra inevitablemente unido al entrenamiento de profesionales autónomos que construyan su propio sistema personal de aprendizaje. Esto implica, en opinión de Osuna y Luna (2008) y Pérez et al. (2015), ir más allá del mero desarrollo de los contenidos curriculares, abarcando la formación de competencias (conocimientos y habilidades) como: las competencias cognitivas (la adquisición de conocimientos técnicos), las competencias sociales (vinculadas al establecimiento de las relaciones, la comunicación y el trabajo en grupo), las éticas (integradas por rasgos como la responsabilidad y los principios morales) y, por último, las emocionales (identificadas por la capacitación afectiva). En definitiva, si la flexibilidad de mercado demanda titulados universitarios que respondan a una formación técnica de calidad, cuyo entrenamiento se ha vinculado tradicionalmente a una inteligencia analítica, y una adecuada formación socio-emocional, más identificada con la inteligencia emocional (en adelante IE), la Universidad debe responder inevitablemente a estas necesidades.

Las estructuras de conocimiento se originan y aplican en contextos sociales concretos, en este sentido, la implementación de metodologías docentes como el aprendizaje cooperativo (en adelante AC), pueden colaborar a su desarrollo, destinado espacio y tiempo a la interacción multidireccional entre pares, sirviendo de complemento a planteamientos más clásicos como la clase magistral, en el que se privilegia la interacción unidireccional o bidireccional entre el profesor y alumno (Traver, 2003). Una perspectiva interaccionista de la enseñanza-aprendizaje plantea el establecimiento de la coyuntura necesaria para que el alumno aprenda a discutir, comparta tareas, asuma responsabilidades y desarrolle la capacidad crítica, entre otras habilidades. Por lo tanto, si la inteligencia está conectada con los afectos se hace necesario la estructuración de los mismos mediante metodologías que, como el trabajo cooperativo, puedan ejercer un importante efecto en su desarrollo (Rosa et al., 2015).

Durante los últimos años, han proliferado las investigaciones que demuestran la enorme influencia que tiene la interacción entre los alumnos en el aula sobre la serie de variables educativas como son el proceso de socialización, la adquisición de competencias o destrezas vinculadas al respeto, la solidaridad, la tolerancia, la empatía, la autoestima o el rendimiento académico, entre otras (Durlak et al., 2011; Fernández-Berrocal y Ramos, 2004; Ovejero, 1990). Variables, todas ellas, que van a repercutir irremediablemente en el desarrollo personal, social y profesional del sujeto (Pérez et al., 2015). En este contexto, el aprendizaje actual se construye a partir de cuatro pilares básicos: aprender a conocer, aprender a hacer, aprender a ser y aprender a vivir juntos (Delors, 1996). La educación debe proporcionar una formación que preste atención al desarrollo de la IE para contribuir a la formación integral del sujeto (Filella et al., 2014). En esta línea, el Espacio Europeo de Educación Superior (en adelante EEES) ha supuesto una profunda reflexión sobre la formación universitaria y la forma de transmitir el conocimiento utilizada por el profesorado. El enfoque docente propuesto por el EEES se basa en la evaluación de las competencias transversales (son genéricas y compartidas por todas las materias o ámbitos de conocimiento) y las competencias específicas (están relacionadas con disciplinas concretas). Las primeras, tal y como se recoge en los Libros Blancos de las titulaciones, se clasifican en: instrumentales (incluyen tanto las habilidades de comunicación e indagación, como el saber hacer o Know how aplicadas al ejercicio de una profesión concreta), interpersonales (miden las habilidades de relación social e integración, la capacidad de trabajar en equipos específicos y multidisciplinares) y sistémicas (miden las cualidades individuales y la motivación) (ANECA, 2005). La adquisición de competencias, en opinión de Riesco (2008), debería incluir tres tipos de resultados: conocimientos o habilidades a adquirir en una materia específica, competencias genéricas que no son propias de una materia concreta aunque podrían trabajarse en ella y las competencias vinculadas a valores o actitudes en función de la materia o del plan de estudios. Inmersos en esta maraña de competencias, en este trabajo, paralelamente al desarrollo de las competencias específicas de la asignatura Técnicas de Ventas, nos centraremos en el desarrollo de aquellas competencias transversales más específicas que, autores como Bisquerra (2003) y Rosa et al., (2014), denominan emocionales. Es decir, en el conjunto de conocimientos, capacidades, habilidades y actitudes necesarios para comprender, expresar y regular de forma apropiada los fenómenos emocionales a los que se tiene que enfrentar un sujeto inmerso en la sociedad. Todo ello implica la necesidad de conceder importancia a la educación afectiva en un sentido más amplio (Barnett et al., 2003; Pérez et al., 2015). Garantizar la formación de buenos profesionales supone ineludiblemente un proceso enseñanza-aprendizaje que incluya, además de la instrucción en el conocimiento técnico, el desarrollo personal del alumno (Rosa et al., 2015). En este sentido, resulta importante estructurar los afectos, para ello el uso de actividades y metodologías como el trabajo cooperativo puede ejercer un papel de importante aliado (Rosa et al., 2015).

Gran parte de las compañías actuales se basan en el desarrollo de equipos de profesionales autogestionados, cuyos empleados son independientes, capaces de autorregular e integrar sus esfuerzos para 
desarrollar una determinada tarea. No obstante, los conocimientos, capacidades y habilidades socioemocionales de los empleados que componen estas organizaciones depende, principalmente, del entrenamiento recibido en el seno de las mismas (Domingo, 2008). Esto ha provocado cierta crítica que, desde el mundo empresarial y académico, han puesto en cuestión la formación de los titulados universitarios en las habilidades socio-emocionales necesarias para el desarrollo del trabajo en grupo y, en general, para su adaptación al mundo laboral y social (Domingo, 2008; Geoffroy, 2014; González-Arias y Alucema, 2015). Si bien, como hemos señalado anteriormente, el estudio de la IE ha sido recurrente en diferentes ámbitos educativos, existe una carestía de trabajos que estudien como potenciar las habilidades necesarias para el desarrollo efectivo de trabajo cooperativo en la formación en marketing y más particularmente en la formación en ventas. En este sentido, si bien resulta deseable un buen desarrollo de las habilidades socio-emocionales para lograr la mayor eficacia del equipo de trabajo para todos los sujetos y en todas las profesiones, en el caso de los profesionales de la venta adquiere mayor importancia. El perfil del vendedor viene asociado a conocimientos, capacidades y habilidades intrínsecamente socioemocionales: autoestima, creatividad, empatía, motivación, habilidades comunicativas (Monferrer et al., 2014). La Universidad, a nuestro entender, debe aceptar el desafío de formar a los alumnos en estas habilidades, potenciando el desarrollo de metodologías de alfabetización emocional para el logro eficaz del trabajo en grupo.

En este trabajo proponemos una experiencia docente llevada a cabo en la asignatura del primer semestre Técnicas de Ventas, obligatoria 4ํㅜ curso del Grado de Administración de Empresas. El objetivo consiste en el desarrollo, no sólo las competencias técnicas del alumnado, sino también las socio-emocionales, preparando así a los futuros vendedores para trabajar cooperativamente en cualquier departamento comercial siendo capaces de afrontar los desafíos del mercado actual. En este trabajo teorizamos en primer lugar sobre el concepto AC y habilidades socio-emocionales, y en segundo lugar relatamos la experiencia docente, analizamos los datos y resultados y finalmente aportamos las conclusiones.

\section{EL APRENDIZAJE COOPERATIVO Y LAS HABILIDADES SOCIO-EMOCIONALES}

El siglo XX fue el periodo más prolífero en el desarrollo de escuelas y corrientes en el campo educativo tanto en lo referente a aportes teóricos, como metodológicos y prácticos. Destacables resultan las aportaciones del paradigma conductista, el humanista, el socio-histórico y el constructivismo social. Sin ánimo de profundizar en los mismos, mencionaremos brevemente que el conductismo, propuso la tecnología educativa y la enseñanza programada; el humanista, la denominada educación personalizada; el cognitivismo, el programa para enseñar a pensar y aprender a aprender; el paradigma socio-histórico, la enseñanza desarrollada y problemática y, por último, el constructivismo, cuestionó la concepción transmisiva del proceso enseñanza-aprendizaje encontrando en el AC el eje vertebrador de su discurso (Ferreiro, 2007).

La introducción del constructivismo como marco explicativo del aprendizaje supuso el inicio de arduo debate que ha enfrentado a los partidarios de una concepción más tradicionalista, en los que el alumno se presenta en una posición inmovilista, frente a los que defienden un papel más activo del mismo. Esta paradigma implica la ruptura con una visión que presenta al docente en un papel jerárquicamente superior, protagonista de un proceso que considera al alumno como un "recipiente" sobre el que "verter" unos contenidos de carácter técnico, dejando al lado la asunción de contenidos procedimentales y actitudinales (Traver, 2003). El constructivismo considera al alumno como piedra angular del proceso de aprendizaje. En este contexto, el profesor adquiere un rol mediador entre el alumno y el conocimiento, se muestra como un guía facilitador del aprendizaje, un diseñador de entornos que motiven y ayuden a alcanzar los resultados esperados. La forma más efectiva de enseñanza, según esta escuela de pensamiento, es la producida cuando se da una interacción cooperativa entre compañeros (Rosa et al., 2014, 2015; Pérez-Serrano, 2006).

Posteriormente, en una época más reciente, surge el conectivismo que parte del análisis de las posibles limitaciones que las corrientes educativas anteriores presentan para explicar el efecto que la tecnología tiene sobre la manera en la que actualmente vivimos, nos comunicamos y aprendemos (Siemens, 2004, 2008; Zapata-Ros, 2015). El punto de inicio del conectivismo es el individuo, el conocimiento personal se hace en una red que alimenta de información a organizaciones e instituciones, las cuales, a su vez, retroalimentan de información a la misma red, que finalmente termina proveyendo de nuevo aprendizaje al individuo (Gravity, 2013). Este ciclo de desarrollo del conocimiento permite a los alumnos mantenerse actualizados en el campo en el cual se han formado conexiones. Siemens indica que para implementar el conectivismo se deben reorganizar las metodologías para permitir que los alumnos formen conexiones basadas en intereses y necesidades. Las herramientas Web 2.0 permiten un diálogo abierto, la construcción de aprendizaje de forma cooperativa, ya no es posible experimentar y adquirir personalmente el aprendizaje, hay que formar conexiones. Las TICs suponen un interesante recurso didáctico que facilita el 
aprendizaje de los conocimientos técnicos de la asignatura así como de desarrollo de ciertas habilidades socio-emocionales. El alumno, mientras interactúa con ellas, requiere movilizar su pensamiento crítico, analítico y su capacidad comunicativa, desarrollando su capacidad para responder a los desafíos y problemas implicados en la materia y en su futuro profesional (Hernández et al., 2014; Miranda et al., 2008). Además el uso de las tecnologías resulta relevante para el AC proporcionando grandes oportunidades de interacción y colaboración tanto dentro del aula como fuera de la misma (Castro y González-Palta, 2016; Hernández et al., 2014; Martí-Vilar, 2013; Ovalles, 2014).

El AC supone un heterogéneo conjunto de métodos de instrucción estructurados, en los que los estudiantes trabajan juntos, en grupo, ayudándose mutuamente en tareas académicas (Kamp et al., 2012; Slavin, 2014; Vallet et al., 2016). Los estudiantes aprenden con, de y por otros compañeros a través de un planteamiento de enseñanza-aprendizaje que facilita una interdependencia positiva y en el que docente y estudiantes actúan como co-aprendices (Fernández-Río, 2014). Los fundamentos del AC están relacionados con la interacción, la construcción social de la inteligencia y el entrenamiento de las habilidades socio-emocionales del alumnado (Ovejero, 1990). Estos postulados no son nuevos y los encontramos anteriormente en la concepción de la educación-aprendizaje defendida por Piaget y Vygotsky o, posteriormente, por la Escuela de Ginebra y la Escuela Soviética. El gran avance en los dictámenes de la Psicología Social Evolutiva se basa en el hecho de hacer hincapié en la importancia de la interacción entre iguales, del conflicto como necesidad para el desarrollo socio-cognitivo del sujeto.

En este sentido, el AC favorece la integración de todos los sujetos participantes. Cada cual aporta al grupo sus habilidades y conocimientos mediante un sistema de reparto de roles. Así, quien tiene mayor capacidad de liderazgo, dirige democráticamente y de forma compartida la actividad; quién es más analítico, es más activo en la planificación; quien es más sintético, facilita la coordinación. Además esta estrategia de gestión del trabajo supone un aumento en el rendimiento del proceso de aprendizaje ya que los objetivos de trabajo autoimpuestos por el propio alumnado motivan un mayor esfuerzo que si los objetivos son impuestos desde el exterior por el propio profesorado. De esta manera el docente no es el fin del aprendizaje, sino una herramienta más, su responsabilidad se centra en enseñar a aprender. El AC implica la construcción y mantenimiento compartido entre alumnos y docentes de la tarea, los objetivos, las responsabilidades y los productos de aprendizaje (Sims, 2003; Vallet et al., 2016). Los agentes educativos implicados en el proceso enseñanza-aprendizaje, docentes y alumnos, tratan de llegar a una definición intersubjetiva de la situación a partir de los significados subjetivos de cada uno de ellos (Torras, 2013) El trabajo cooperativo amplía el campo de experiencia del alumnado y aumenta sus habilidades comunicativas al entrenarlos en el reconocimiento del resto de perspectivas, potenciando las habilidades socio-emocionales, ya sea para defender los propios argumentos o para aceptar los de los demás. En definitiva, parafraseando a Kagan (1992), el AC supone el mayor ejemplo de que: "la suma de las partes interactuando es mejor que la suma de las partes solas".

Llegado a este punto, tal y como señala Ovejero (1990) y Vallet et al. (2016), es importante aclarar que si bien todo AC es aprendizaje en grupo no todo aprendizaje en grupo es AC. La distribución de los alumnos pequeños grupos de trabajo pone a los alumnos en situación de relacionarse entre ellos (bien físicamente, bien virtualmente a través de la TIC's), sin embargo, la naturaleza de la relación variará en función de cómo se estructure el grupo y, obviamente, las particularidades de la actividad. En este sentido, uno de los principales errores cometidos en iniciados en esta metodología es organizar la clase en grupos para posteriormente plantear propuestas educativas de carácter individual, esto puede ser trabajo en grupo, aunque no necesariamente cooperativo. Las principales diferencias entre las técnicas de AC y las de aprendizaje grupal son: (i) Interdependencia positiva entre los miembros del grupo; (ii) Existencia de responsabilidad individual y corresponsabilidad entre los miembros del grupo; (iii) La composición de los grupos de trabajo cooperativos es heterogénea; (iv) En el trabajo cooperativo se produce un liderazgo compartido; (v) Las habilidades necesarias para desarrollar el AC son objeto explícito de la intervención educativa.

(i) Interdependencia positiva entre los miembros del grupo. Esto supone que el aprendizaje de los miembros del grupo a nivel individual se reduce sin la contribución del resto. Para potenciar la interdependencia positiva hay que entrenar al alumno en la idea de que la realización de las producciones de clase son objetivos colectivos del grupo, el éxito personal va ligado inevitablemente al del grupo. En este sentido, existen diversas formas de estructurar la interdependencia positiva, por ejemplo: las recompensas colectivas, la dependencia de recursos de otros, la división del trabajo, etc.

(ii) Existencia tanto de responsabilidad individual como corresponsabilidad entre los miembros del grupo. Es decir, los resultados dependen del aprendizaje individual de todos los miembros del grupo. Con la potenciación de la responsabilidad individual se trata de evitar que haya algún miembro que no trabaje y de que todo el trabajo del grupo recaiga en una sola persona. Algunas fórmulas usualmente utilizadas para 
controlar el desempeño individual de los miembros del grupo son: los exámenes individuales, la elección al azar de un estudiante para presentar los resultados del grupo (portavoz), o hacer preguntas individuales mientras se supervisa el trabajo grupal (Domingo, 2008).

(iii) La composición de los grupos de trabajo cooperativos es heterogénea mientras que en el trabajo en equipo suele ser homogénea. La formación de los grupos heterogéneos debe ir acompañada de la construcción de la identidad de los grupos, de la práctica de la ayuda mutua entre el alumnado que debe aprender a valorar las diferencias individuales de manera que estas les permitan desarrollar la sinergia del grupo.

(iv) En el trabajo cooperativo se produce un liderazgo compartido y no un liderazgo individual más propio del trabajo en equipo. Algunas de las características del AC están en sintonía con el desarrollo del concepto moderno de liderazgo, que enfatiza la cooperación, el liderazgo en equipos y el reconocimiento de las perspectivas múltiples.

(v) Las habilidades necesarias para desarrollar el AC son objeto explícito de la intervención educativa, son enseñadas directamente por los profesores, previamente y durante el proceso de implantación en el aula. Esta conclusión no suele darse en el trabajo en equipo, puesto que en este segundo caso se presupone que las habilidades socio-emocionales y las capacidades que los alumnos necesitan para trabajar en grupo son un prerrequisito que deben poseer antes de tomar la decisión de utilizar dinámicas grupales.

A la vista de estas características o elementos centrales del AC, queda claro que, para llevarlo a cabo eficazmente hay que buscar la correspondencia entre los objetivos de la asignatura y las demandas en el alumnado tanto a nivel cognoscitivo o técnico como emocional. A continuación vamos a profundizar en las habilidades necesarias a entrenar para el desarrollo del AC.

\section{Las habilidades socio-emocionales o la inteligencia emocional}

En apartado introductorio señalábamos la reivindicación por parte del mundo empresarial de la necesidad del entrenamiento de los titulados universitarios en las habilidades socio-emocionales con el fin de posibilitar una mayor integración en los diferentes grupos humanos y una mejor adaptación a las demandas y necesidades sociales. El trabajo cooperativo valora la interacción, la colaboración, la empatía, el respeto así como la resolución de conflictos y la responsabilidad (André et al., 2013, Darnis y Lafont, 2013; FernándezRío, 2016). Los modelos educativos tradicionales fomentan el trabajo individualista en el que sólo se da prioridad al logro individual y, por tanto, a la competitividad, la jerarquía y la división del trabajo en pequeñas tareas, lo que hace que se pierda el sentido de lo que se está haciendo, desmotive a las personas y no siempre resulte eficiente (Domingo, 2008).

Para trabajar en grupos cooperativos, los alumnos deben aumentar sus habilidades socio-emocionales, es decir, deben aprender a auto-organizarse, a escucharse entre sí, a distribuirse el trabajo, a resolver los conflictos, a asumir responsabilidades y a coordinar las tareas, entre otras. Para lograr el entrenamiento de las mismas, se hace necesario el desarrollo de interacciones cooperativas que faciliten los procesos cognitivos del proceso enseñanza-aprendizaje y los afectivo-relacionales vinculados a las actitudes y valores, en definitiva, desarrollar programas de acción fundamentados en la IE. El buen desarrollo de la IE contribuye a promover las relaciones entre los miembros de un grupo fomentando la colaboración entre los mismos (Druskat y Wheeler, 2003; Goleman, 1995,1998, 2000; Goleman et al., 2002; Li et al., 2016; Schumacher y Wheeler, 2009).

Llegados a este punto, sin ánimo de profundizar, haremos un breve repaso histórico a la forma en la que se ha abordado el estudio de la IE y de las habilidades socio-emocionales en la literatura. En este sentido, las principales perspectivas de análisis han sido dos: 1) los modelos teóricos de habilidad (centrados en las habilidades mentales que permiten utilizar la información proporcionada por las emociones para mejorar el procesamiento cognitivo); 2) los modelos mixtos (aquellos que combinan las habilidades mentales con rasgos de personalidad). La IE, según los defensores de los modelos de habilidad (Mayer y Salovey, 1997), supone un conjunto de capacidades cognitivas interrelacionadas que representa la intersección de la capacidad mental general (razonamiento) y las emociones, diferenciándose de los rasgos de personalidad y comportamiento (empatía, asertividad, etc.), defendidos por los modelos mixtos. Modelos, que si bien resultan más generalistas y difusos, han sido ampliamente acogidos por la población en general, la comunidad científica, educativa y el mundo empresarial, gracias a la particular interpretación realizada por Goleman (1995, 1998) de la estructura propuesta en 1990 por Salovey y Mayer. Este autor, a través del "best seller" Emotional Intelligence afirma que, junto a otros atributos, la aportación de la IE al éxito en la vida es superior a la del cociente intelectual. 
Volviendo a los orígenes, la IE, tal y como es concebida por Mayer y Salovey (1997), se refiere a la capacidad de reconocer los propios sentimientos y los ajenos, de manejar bien las emociones tanto en relación con uno mismo como con los demás. Supone la adaptación de las emociones por parte del sujeto con el fin de solucionar conflictos (Doucet et al., 2016). Las personas con una alta IE generan planes flexibles, organizan su memoria y usan creativamente la información, pudiendo interrumpir así en otros procesos mentales, respondiendo ante una situación concreta de la forma más eficaz posible (Momm et al., 2015). La importancia de la IE radica en aprender a administrar las emociones para que éstas trabajen a favor de la persona y también del grupo. El término IE describe aptitudes complementarias, distintas de la inteligencia estándar o académica y a las habilidades puramente cognitivas medidas por el cociente intelectual (Cl) (Garaigordobil y Oñederra, 2010; Klare et al., 2014).

Mayer y Salovey consideran que la IE se conceptualiza a través de ciertas habilidades básicas, que son: 1) la habilidad para percibir, valorar y expresar emociones con exactitud; 2) la habilidad para comprender emociones y el conocimiento emocional y 3 ) la habilidad para regular las emociones promoviendo un crecimiento emocional e intelectual (Mayer y Salovey, 1997). Los autores plantean el modelo como un conjunto de habilidades de carácter ascendente, jerárquicamente piramidal, en la que un primer estadio, en la base de la pirámide, se ubican los procesos psicológicos más básicos; la percepción, evaluación y expresión de las emociones; en un estadio intermedio, las habilidades relacionadas con la asimilación y la comprensión emocional; y finalmente, las habilidades más complejas, las referentes a la regulación de las emociones. En este sentido, si pretendemos potenciar la IE de los estudiantes logrando así un mayor AC, se hace necesario establecer una metodología que venga acompañada de actividades y de dinámicas pedagógicas que favorezcan su desarrollo. Resulta fundamental la utilización de técnicas de trabajo en grupo que desarrollen las habilidades socio-emocionales necesarias para el correcto desarrollo de la AC, de no ser así, se corre el riesgo de utilizar técnicas individualistas que conviertan en improductivo cualquier esfuerzo común. Estas habilidades deben ser enseñadas por el profesor de manera intencionada y precisa como las habilidades académicas (Domingo, 2008). El estudio de casos, las dinámicas, las puestas en común, las discusiones de ideas, las decisiones por consenso, el uso de las TIC's, etc., son técnicas a tener en cuenta (Domingo, 2008). A continuación vamos a describir cómo algunas de estas fueron llevadas a la práctica en la asignatura objeto de este trabajo analizando los resultados obtenidos en el proceso enseñanza-aprendizaje de los futuros profesionales de la venta.

\section{METODOLOGÍA}

Las posibilidades existentes para el desarrollo de las habilidades socio-emocionales en el desarrollo de la metodología de AC son muy extensas. Cuatro son los modelos frecuentemente desarrollados para el logro del AC: Jigsaw (Rompecabezas), Student Team Learning (Aprendizaje por Equipos), Learning Together (Aprendiendo Juntos) y Group Investigation (Investigación en Grupo). Otros métodos son: Scripted Cooperation (Cooperación Guiada), Peer Tutoring (Tutoría entre Iguales) y Co-op co-op (Técnica flexible de AC) (Walters, 2000). Cualquiera de estas técnicas así como otras de reciente creación resultan válidas siempre y cuando se respeten las siguientes premisas: los alumnos aprendan en lugar de ser enseñados por el profesor, se trabaja en grupo y cada estudiante desempeña un rol, los integrantes del grupo dependen unos de otros, existe responsabilidad individual y grupal, existe una reflexión personal sobre la efectividad del grupo y se desarrollan las habilidades socio-emocionales (Domingo, 2008). En este sentido, se propone esta experiencia en la que se pretende mejorar los conocimientos técnicos y las habilidades socio-emocionales de los alumnos con el fin de mejorar personal y profesionalmente, ayudándoles así en el desarrollo futuro de su labor de venta.

De forma más específica, a lo largo de los siguientes apartados se muestra una descripción de las fases asociadas a la ejecución de la experiencia, consistente en el diseño de una programación secuencial de técnicas de formación de equipos, talleres, actividades y casos docentes. Al desarrollo de estas acciones le acompaña la implementación de un trabajo de campo mediante el uso de cuestionarios (con su respectiva validación de las propiedades psicométricas del instrumento de medida), para el posterior análisis descriptivo de los datos y la aplicación de tests correlacionales.

\section{Objetivos}

El planteamiento de los objetivos a alcanzar supone, en gran medida, la adaptación en el contexto de la asignatura Técnicas de Ventas de algunas de las recomendaciones propuestas por Brackett et al. (2008). Los autores establecen que cualquier programa de aprendizaje basado en el desarrollo de las habilidades socio-emocionales debe hacer lo que se detalla en lo que sigue. 
1) Enseñar cómo aplicar las habilidades socio-emocionales dentro y fuera del aula. Esto supone la necesidad de proveer al alumno de herramientas socio-emocionales que le permitan enfrentarse exitosamente a los retos derivados de la venta.

2) Crear ambientes de aprendizaje atractivos para el alumno. El AC sitúa al alumno, tal y como recomienda el EEES, como parte activa de su proceso de aprendizaje, estimulando la reflexión, el debate y la implicación. Esta experiencia busca generar un buen clima cimentándose en las oportunidades ofrecidas por el AC.

(3) Formar a los alumnos tanto en las competencias específicas como en las transversales en un contexto de aprendizaje activo y cooperativo. Para ello, además del aprendizaje técnico propio de la asignatura, se ha buscado desarrollar ciertas competencias transversales de ámbito socio-emocional. Para ello se plantea llevar a cabo acciones para el entrenamiento de la percepción, asimilación y comprensión de las emociones en general, manifestando un interés especial en aquellas habilidades socio-emocionales más necesarias para lograr un desarrollo óptimo de la venta: la comunicación, capacidad de escucha, negociación, creatividad, respeto, tolerancia, flexibilidad, empatía, cooperación y la asunción de responsabilidades (Monferrer et al., 2014).

(4) Realizar evaluaciones y acciones de control sobre el desarrollo de la experiencia docente. En este sentido, se proponen ciertas actividades para la autoevaluación individual y conjunta de las habilidades socio-emocionales del alumnado. Así, los participantes en este proyecto pueden reflexionar sobre su capacidad de percepción, asimilación y comprensión de las emociones y, más concretamente, sobre aquellas que han sido trabajadas más específicamente en la asignatura.

El objetivo en última estancia ha sido despertar la curiosidad del estudiante sobre la IE y la importancia de las emociones para la práctica profesional de la venta.

\section{Participantes}

La muestra sobre la que se implementa la experiencia se corresponde con los estudiantes matriculados en la asignatura obligatoria de cuarto curso Técnicas de Ventas del Grado en Administración de Empresas de la Universitat Jaume I. Esto supone una muestra de conveniencia constituida por 121 alumnos, de los cuales un total de 71 son de género femenino (58,7\%) y 50 de género masculino (41,3\%). La edad media de estos estudiantes es de entre 21 y 22 años.

\section{Procedimiento}

Esta experiencia docente se ha desarrollado en 5 fases. FASE 1: Se han formado los equipos de trabajo. FASE 2: Un experto en IE ha impartido un seminario sobre el conocimiento teórico/práctico de las emociones subrayando la importancia de su entrenamiento para ser buenos vendedores. FASE 3: A través de un taller de AC se han desarrollado actividades para la práctica de las habilidades socio-emocionales de la clase. FASE 4: A través de los casos prácticos y de dinámicas grupales se ha consolidado el aprendizaje técnico y se han entrenado las habilidades socio-emocionales. FASE 5: Control y evaluación de la experiencia. A continuación pasamos a describir de forma más detallada en qué han consistido estas fases:

\section{FASE 1: Constitución de equipos.}

En la primera sesión de práctica se han formado los equipos de trabajo en base al Modelo del Cerebro Total (Herrmann, 1989). El Modelo del Cerebro Total integra la neocorteza (hemisferio izquierdo y derecho) con el sistema límbico dividiéndolos en cuatro cuadrantes interrelacionados que constituyen modalidades autónomas de procesamiento diferencial de la información, las cuales pueden ser convenientemente desplegadas en los diferentes procesos del funcionamiento cerebral. Con la aplicación del Instrumento de Dominancia Cerebral de Herrmann (HBDI) se detecta el perfil de combinación de cuadrantes, el cual indica qué cuadrantes son dominantes, formando así cuatro modalidades de pensamiento: 1) realista, propio del hemisferio izquierdo (cuadrantes A y B); 2) idealista, propio del hemisferio derecho (cuadrantes $C$ y D); 3) pragmático (cuadrantes $A$ y D); e instintivo (cuadrantes $\mathrm{B}$ y $\mathrm{C}$ ). Todo sujeto manifiesta una dominancia cerebral, es decir, una tendencia a utilizar más las funciones de un hemisferio que las de otro para interactuar con su medio, en uno/s cuadrante/s u otro/s. La mayoría de los sujetos procesa la información desde varios cuadrantes. El HBDI permite determinar el perfil distintivo de los estudiantes estableciendo la dominancia según las puntuaciones alcanzadas en el cuestionario. Así pues, en esta fase, previa explicación teórica de este modelo, se ha pasado el cuestionario elaborado por Jiménez (2006) que supone la adaptación del cuestionario original de Herrmann al contexto español. El objetivo ha sido formar equipos heterogéneos en relación a la composición de sus miembros (nos aseguramos de que en cada grupo hay alumnos con dominancias en todos los cuadrantes) y a la vez homogéneos entre sí (se mantiene esta misma composición en todos los grupos). Con ello se obliga a los estudiantes a esforzarse en cultivar sus 
habilidades socio-emocionales para poder trabajar cooperativamente con todos los miembros del equipo (Segarra et al., 2015). Por último, una vez analizados los resultados, se ha publicado a través del aula virtual de la asignatura la configuración de los equipos de trabajo.

\section{FASE 2. Taller para el entrenamiento de habilidades socio-emocionales.}

Durante la segunda semana del curso, mediante un taller de dos horas de duración, un psicólogo experto en IE ha impartido contenidos teórico-prácticos básicos para un mejor conocimiento de la misma. En el mismo, a través de una versión adaptada del test de ejecución Mayer-Salovey-Caruso Emotional Intelligence Test (MSCEIT; Mayer et al., 2002), se ha invitado a los alumnos a la reflexión sobre sus conocimientos emocionales, tanto de los propios como de los ajenos. El objetivo del MSCEIT no es, en este caso, servir de instrumento de medida sobre la IE, sino constituirse como un recurso didáctico que estimule al alumno hacia su alfabetización emocional. En esta jornada se ha trabajado sobre el entrenamiento en el conocimiento de la percepción, la asimilación, la comprensión y la regulación emocional. Las acciones emprendidas en el taller han sido las siguientes:

En lo referente al entrenamiento de la percepción y asimilación emocional se han propuesto dos tareas. La primera ha consistido en pedir al estudiante que identificara y etiquetara las emociones positivas y negativas que experimentadas en las últimas 24 horas. La segunda ha tenido como objetivo valorar la capacidad del alumno para percibir las emociones de los demás. Para ello se ha utilizado una aplicación informática en la que aparecían diversos rostros que se reflejaban diferentes micro-expresiones, el alumno ha tenido que diferenciarlas.

Para mejorar la comprensión emocional se ha diseñado un mapa de emociones, en el eje de abscisas se ha representado el AFECTO (bajo/alto) y en el de ordenadas la ENERGIA (baja/alta) y se ha pedido al alumno que sitúe su situación actual dentro del mapa así cómo dónde cree que sería conveniente estar. La misma iniciativa se ha trasladado al contexto de la venta distinguiendo el lugar óptimo dónde debe situarse el vendedor según la etapa del proceso de venta en el que se encuentre (acercamiento, prospección, negociación, cierre...). Por último, para entrenar la regulación emocional se ha presentado a los alumnos mediante un power-point varias viñetas en las que los estudiantes han tenido que valorar el comportamiento de los personajes representados en las imágenes y las consecuencias que pudieran tener sus actos para otros.

El objetivo de este taller ha sido lograr el autoanálisis de las propias habilidades socio-emocionales de los estudiantes. En esta actividad los alumnos han observado sus posibles déficits en la percepción, la asimilación, la comprensión y la regulación de las emociones. Esta reflexión subjetiva ha sido completada por un informe realizado por el psicólogo según los resultados obtenidos por los alumnos al responder al Trait Meta-Mood Scale (TMMS-24; Fernández-Berrocal et al., 2004; original de Salovey et al., 1995) enlazado en el aula virtual de la asignatura. El análisis de sus resultados ha permitido un diagnóstico emocional del alumno lo que ha permitido aconsejar sobre las acciones a emprender en cada caso particular.

\section{FASE 3. Taller de aprendizaje cooperativo.}

Es un error incurrir en la idea de que el alumno acude al aula con un efectivo desarrollo las habilidades socio-emocionales que le posibilitarán el desarrollo de un aprendizaje activo. En este sentido, resulta indispensable que el profesor facilite estrategias y técnicas que ayuden al alumno a consolidar estas habilidades junto a las competencias técnicas de la asignatura. Si bien en la fase anterior se ha intentado concienciar a los alumnos sobre la importancia de la percepción, comprensión y regulación de las emociones, en ésta, estas capacidades han sido practicadas grupalmente. A continuación describiremos las actividades que se han planteado a lo largo de una jornada de cuatro horas que tuvo lugar la cuarta semana de curso:

Actividad "El desafío del Malvavisco": Este ejercicio, diseñado por Skillman (2010), revela profundas lecciones sobre la naturaleza de la colaboración. Para su ejecución se ha pedido a los alumnos que construyan la estructura autónoma más alta que sean capaces de hacer con 20 espaguetis, un metro de cinta adhesiva, un metro de cuerda y un malvavisco (una chuchería). El malvavisco debía ir arriba de todo. Los alumnos han comenzado orientándose en la tarea, discutiendo y calculando como se verá la estructura, disputando el poder, planificando y organizando durante todo el proceso. Los equipos que más éxito han tenido en el desarrollo del desafío son los que han trabajado de forma cooperativa, especializada, creativa y repartiendo los roles de trabajo (Figura 1). 
Actividad "Presión grupal": Se les ha presentado una foto en la que un grupo de personas aparecían abalanzadas unas sobre otras con el fin de hacerse con una bandera. Se les ha pedido a los alumnos que analizasen esta fotografía describiendo lo que veían, lo que les evocaba y lo que les sugería sobre el trabajo en grupo, de estos comentarios se han extraído conclusiones sobre lo que implica la cooperación. A través de esta actividad, mediante un debate en clase, se ha perseguido sensibilizar sobre la importancia de crear un ambiente de cooperación en el grupo en yuxtaposición a la imagen de la fotografía que reflejaba un ejercicio de competición.
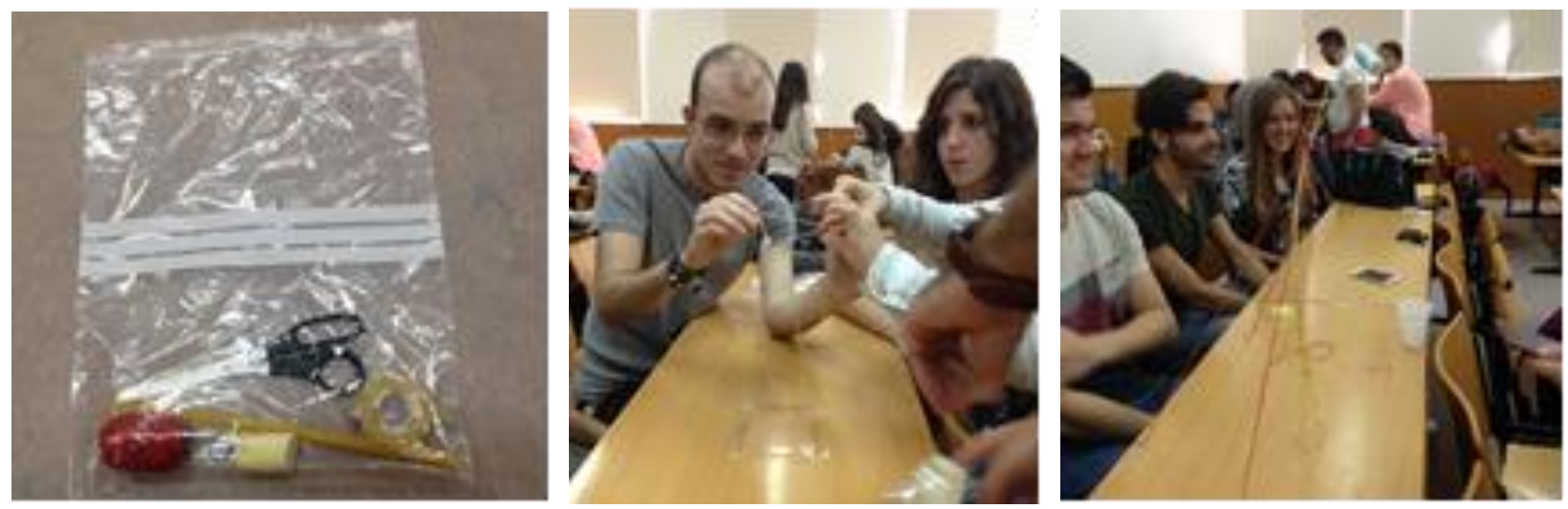

Fig. 1: La implementación de la dinámica "El desafío del Malvavisco" en el aula

Actividad "Los seis sombreros de pensar": Es una técnica propuesta por Bono (1985) para fomentar el logro de decisiones grupales. El método de los seis sombreros intenta simular lo que ocurre en la mente humana adoptando el símil de un sombrero. Cada uno de los seis sombreros es de un color diferente, lo que simboliza las diferentes formas en las que se puede observar la realidad. En este sentido, se ha provisto a los equipos de los diferentes sombreros y se les ha presentado una reclamación de ventas que han tenido que solucionar según la forma de pensar propia de cada sombrero. Así, por ejemplo, si se está con el sombrero blanco, el punto de vista del alumno tiene que ser lo más neutral posible, analizando los datos, hechos o cifras. Por el contrario, si utilizamos el sombrero rojo, la visión puede ser más subjetiva y guiarse por las emociones, los sentimientos o las intuiciones. La meta de esta actividad es encontrar una descripción poliédrica de los problemas sin tratar de juzgar a priori lo que está bien o está mal, lo correcto o incorrecto. La idea se basa en descubrir las diferentes facetas de la realidad, hacer visibles los aspectos que puedan permanecer ocultos y facilitar el proceso final de toma de decisiones que resuelva la reclamación propuesta.

Actividad "Bendita Venta". Argumentábamos anteriormente las posibilidades que un buen desarrollo del TIC's tiene sobre el AC y sobre el entrenamiento de las habilidades socio-emocionales. En este sentido, junto al aula virtual (soporte en el que se han colgado las transparencias, enlaces a videos de Youtube, artículos, foro para el intercambio de información, la encuestas virtuales para valorar la IE y el grado de satisfacción con la experiencia, etc.) se ha puesto en marcha un grupo de Facebook. El mismo, de incorporación voluntaria, se ha llamado "Bendita Venta" fruto de una tormenta de ideas (brainstorming) y la posterior votación por parte del alumnado. El objetivo del mismo ha sido servir de estímulo para el intercambio de ideas entre los alumnos con respecto a aspectos vinculados a la asignatura. Además ha supuesto un interesante medio para el desarrollo de la colaboración, la creatividad, la crítica constructiva y la comunicación. En este sentido se han colgado videos, comentarios sobre los contenidos vistos en clase, presentaciones, artículos, dudas sobre cómo abordar el estudio de la asignatura, ofertas de empleo para vendedores, etc. Semanalmente se ha valorado el contenido que más "me gusta" ha recibido y al finalizar el curso el equipo más puntuado ha recibido una bonificación en la evaluación de las prácticas de 0,25 puntos.

Role Playing "La chistera". En esta actividad el portavoz de cada equipo ha sacado de una chistera un objeto aparentemente inservible. Posteriormente, con ayuda de su equipo ha buscado posibles usos al producto, ideando un argumentario de venta para intentar "venderlo". Mientras que el portavoz presentaba el producto públicamente, sus compañeros de clase (clientes) han planteado objeciones al mismo que el equipo ha tenido que solventar. Esta actividad ha sido grabada y visualizada posteriormente en el aula. Esto ha permitido que el alumno que ha ejercido el rol de "vendedor" pudiera hacer un análisis de su actuación y plantearse posibles acciones de mejora. Mientras, el resto de compañeros, han podido observar otros estilos comunicativos aprendiendo de la experiencia de otros. Con esta experiencia se han trabajado concretamente habilidades como: la creatividad, la capacidad crítica, la comunicación, entre otras. Todas las actividades descritas han sido evaluadas cualitativamente a través de los comentarios y propuestas de mejora enunciados por los profesores y por los compañeros. 


\section{FASE 4. Casos y dinámicas.}

Esta fase tiene su desarrollo a lo largo de todo el curso y se ha ejecutado a lo largo de las dos horas de duración de las sesiones prácticas de la asignatura. A través de los casos prácticos se ha consolidado el aprendizaje técnico de la asignatura y se han desarrollado las habilidades socio-emocionales. En todas las sesiones se han resuelto casos prácticos (durante la primera hora y media) y se han presentado dinámicas grupales (la última media hora de clase). Pasamos a describir ciertos detalles de las mismas:

Casos técnicos: Diseñados para consolidar los contenidos teóricos aprendidos simultáneamente al desarrollo de las habilidades socio-emocionales del alumno. Sirva como ejemplo el caso referido a "la atención al cliente". En el mismo, cada equipo ha tenido que solucionar una reclamación oral y escrita venciendo los obstáculos interpuestos en el caso y aplicando los conocimientos técnicos y sus habilidades socio-emocionales (asertividad, empatía o negociación). En este sentido se ha presentado hasta un total de 7 casos referentes a las fases del proceso de venta, la negociación comercial, el cierre y la ética en la ventas, entre otros. Los casos se han corregido en clase, siendo objeto de discusión y debate entre los compañeros, contando con la mediación del profesor. Al finalizar la sesión, los alumnos han tenido que puntuar su propia actuación, por un lado, en lo referente a su capacitación técnica para resolver el caso, por otro, en lo referente al desarrollo de sus habilidades socio-emocionales en lo que al seguimiento de la participación en el debate se refiere.

Dinámica "La herencia del indiano": Se ha planteado una dinámica que describe la recepción en una ONG de una herencia cuyo donante es un indiano fallecido. Los alumnos han tenido que decidir de entre diez posibles opciones sobre dónde invertir el dinero además de convencer a sus compañeros sobre su postura. Paralelamente se han distribuido diferentes papeles entre los miembros del equipo que reflejan circunstancias particulares que van a condicionar la elección de una opción u otra. Por ejemplo: el papel del estudiante número 1 representa al de una persona que tiene un interés personal en destinar el dinero de la herencia a cursos de formación profesional para emigrantes ya que espera contratar a su novia como profesora de estas acciones formativas. Este ejercicio ha servido para entrenar las habilidades de comunicación, escucha activa, negociación y ética, entre otras.

Dinámica "Gane el máximo posible": Esta actividad se ha centrado en ganar lo máximo posible como el criterio principal del equipo. Se han formado 4 equipos que han negociado el reparto de 10000 puntos. A lo largo de 10 vueltas cada equipo, representado por su portavoz, ha elegido entre una " $X$ " 0 una " $Y$ " estudiando cuidadosamente la tabla de valores presentada, mostrando a mano alzada el cartón con sus elección. Así, si el resultado de las elecciones efectuadas por los equipos ha sido de " $4 X$ ", cada " $X$ " ha perdido 100 puntos. Si por el contrario, el resultado ha sido de " $3 X+1 Y$ ", las " $X$ " han ganado 100 puntos y la " $Y$ " han perdido 300 puntos. Si el resultado ha sido de " $2 x+2 Y$ ", cada " $X$ " gana 200 puntos y cada " $Y$ " ha perdido 200 puntos. La combinación " $1 X+3 Y$ " ha supuesto que cada " $X$ " ha ganado 300 puntos y cada " $Y$ " ha perdido 100 puntos. Por último, la elección de "4Y" ha implicado que cada "Y" haya ganado 100 puntos. En las rondas 5, 8 y 10 las ganancias o pérdidas se han multiplicado por 3, 5 y 10 siendo precedidas por una negociación entre los portavoces de cada equipo. El objetivo de esta dinámica ha sido ayudar a cimentar la necesidad de llegar al consenso como base de la cooperación, la negociación y la resolución de conflictos.

Dinámica "La ética en la venta": Esta acción supone el visionado del cortometraje "Allanamiento de Morada", en el que los protagonistas (vendedores de enciclopedias a "puerta fría") ejercen una venta a presión, "obligando" a que la clienta les compre una enciclopedia pese a no necesitarla. Finalizada la película se ha generado un debate ético entre los alumnos de la clase. Los equipos han decidido su posicionamiento sobre la película, elaborando la estrategia a defender ante sus compañeros. Esta dinámica ha pretendido desarrollar comportamientos morales en los futuros vendedores simultáneamente al entrenamiento de otras habilidades como la capacidad crítica, la comunicación, la capacidad de escucha, etc.

\section{FASE 5: Control y evaluación de la experiencia.}

Esta fase supone el análisis de la consecución de los resultados obtenidos con la experiencia docente. Así, se ha habilitado en el aula virtual dos enlaces, uno con una encuesta para la valoración de la IE del alumno y, el otro, para conocer el grado de satisfacción con la experiencia docente. Los resultados obtenidos nos han permitido llegar a ciertas conclusiones que han sido expuestas en las conclusiones.

\section{Instrumento de medida}

Las aproximaciones con las que tradicionalmente se ha abordado la medición de la IE son: los instrumentos de auto-informe, los test de ejecución y los informes de observadores externos, medidas que, como es 
habitual en la literatura, no se encuentran exentas de polémica. Concretamente, el modelo de Mayer y Salovey, ha basado sus investigaciones en los dos primeros métodos. Los auto-informes se basan en la percepción del sujeto sobre sus habilidades socio-emocionales mientras que los test de ejecución suponen la implementación de tareas que evalúan las respuestas y conocimiento emocional. Su fácil comprensión y sencillez en la administración ha provocado que sean los instrumentos más ampliamente utilizados. En este sentido, Salovey et al. (1995) desarrollan un instrumento de auto-informe para la evaluación de la IE percibida denominado Trait Meta-Mood Scale. Concretamente, en este caso, para evaluar la IE se utiliza la versión castellana y reducida del Trait Meta-Mood Scale (TMMS-24; Fernández-Berrocal et al., 2004; original de Salovey et al. (1995) sin evaluar otras opciones como el test de ejecución de MSCEIT, que si bien se utiliza para el diseño de las actividades de entrenamiento de este proyecto (ver la FASE 2), no es utilizado como instrumentos de medida. El TMMS-24, tal y como se recoge en la Tabla 1, se trata de una escala rasgo de meta-conocimiento de los estados emocionales que proporciona, a través de 24 ítems y una escala Likert (1-5 puntos), el índice de IE percibida mediante tres factores (donde 1 es "totalmente en desacuerdo" y 5 es "totalmente de acuerdo"): percepción, comprensión y regulación de las propias emociones (con 8 ítems para cada factor). La percepción de las emociones implica el grado en el sujeto presta atención a sus propias emociones; la comprensión se refiere a su habilidad para entender y asimilar las emociones percibidas; y la regulación emocional se refiere a la capacidad que tiene el sujeto para bloquear las emociones negativas y potenciar las positivas (Extremera et al., 2007).

En relación a la medición del grado de satisfacción del alumno con respecto su AC recurrimos a la escala de medida desarrollada por Viles et al. (2013). Este instrumento de medida se compone de un total de 23 ítems en el que el alumno debe mostrar, en una escala tipo Likert de 5 puntos, su grado de acuerdo con una serie de afirmaciones relacionadas con el funcionamiento de su grupo de trabajo a lo largo del semestre (donde 1 es "totalmente en desacuerdo" y 5 es "totalmente de acuerdo") sobre una serie de dimensiones fundamentales: la participación en la toma de decisiones (3 ítems), la gestión de conflictos (2 ítems), la resolución de problemas (2 ítems), la colaboración (3 ítems), el liderazgo (2 ítems), la confianza (3 ítems) y la retroalimentación (8 ítems).

\section{Validación del instrumento de medida}

La depuración de las escalas se realizó mediante análisis factorial confirmatorio por modelos de ecuaciones estructurales a través del programa estadístico EQS 6.1. Los parámetros fueron estimados utilizando el enfoque de máxima verosimilitud por método robusto.

En concreto, se sigue una estrategia de desarrollo del modelo (Hair et al., 2009). Así, en base a la asunción de estructuras de variable latente para los diferentes constructos, se lleva a cabo un procedimiento de perfeccionamiento progresivo de los modelos iniciales a través de la supresión de los indicadores menos adecuados. A este respecto, tomando como base las recomendaciones de Jöreskog y Sörbom (1993), en primer lugar se procedió al examen de los parámetros de estimación. Aquellos indicadores que no cumplían la condición de convergencia fuerte, con coeficientes estandarizados individuales $(\lambda)$ por debajo de 0,6 y con un valor promedio de las cargas sobre cada factor por debajo de 0,7 fueron eliminados (Bagozzi y Youjae, 1988; Steenkamp y Van Trijp, 1991; Hair et al., 2009). A continuación se verifica el cumplimiento de la condición de convergencia débil a través del análisis de la significatividad de los coeficientes de regresión de los factores con respecto a su correspondiente variable latente (Steenkamp y Van Trijp 1991). Para ello se revisa la significatividad del estadístico $t$ de student exigiendo un requisito máximo $(t>2.58 ; P=0.01)$. $A$ través de este proceso se eliminaron los indicadores PERCE.5, PERCE.6, COMPR.4, COMPR.5, COMPR.8, REGUL.5, REGUL.7 y REGUL.8 de la escala de medición de la IE y los indicadores DECIS.1, RETRO.7 y RETRO.8 de la escala de satisfacción en el AC del estudiante. Finalmente, se supervisa la evolución de los principales índices de ajuste del modelo conforme se procede a la eliminación de los indicadores. Concretamente el ajuste del modelo conceptual a los datos empíricos se estudia a través de los estadísticos: $X 2$, normed fit index (NFI), non-normed fit index (NNFI), incremental fit index (IFI), comparative fit index (CFI), goodness-of-fit index (GFI), root mean square residual (RMR) y root mean square of approximation (RMSEA).

Seguidamente, con tal de verificar si el proceso de depuración no había perjudicado al nivel de fiabilidad de las escalas se realizaron diversas pruebas: el análisis del coeficiente de fiabilidad para valorar la consistencia interna a partir del a de Cronbach (Nunnally 1979), así como la fiabilidad compuesta del constructo (FC). En ambos casos se consideran como aceptables valores superiores a 0,7 (Fornell y Lacker 1981; Hair et al. 2009). Adicionalmente se realiza el análisis de la varianza extraída (VE), debiendo ser ésta superior a 0,5 (Fornell y Lacker 1981; Hair et al. 2009). Toda esta información queda recogida en la Tabla 1. 
Tabla 1: Resumen de los análisis descriptivos, factoriales, de validez y de fiabilidad de las escalas de medición. (Nota: $\mathrm{x}$ recoge el valor promedio, $S^{2}$ la varianza del factor, * $\left.p<0.01\right)$

\begin{tabular}{|c|c|c|c|c|}
\hline \multicolumn{5}{|l|}{ Inteligencia Emocional del Estudiante $(\mathrm{FC}=0,77 ; \mathrm{VE}=0,52)$} \\
\hline Percepción: $\lambda=0,730 ;$ Sig. $=5,022(\alpha=0,856 ; F C=0,86 ; \mathrm{VE}=0,50)$ & $\mathrm{x}$ & $S^{2}$ & $\lambda$ & Sig. \\
\hline PERCE.1 - Presto mucha atención a los sentimientos. & 4,13 & 0,50 & 0,655 & Fijado \\
\hline PERCE.2 - Normalmente me preocupo mucho por lo que siento. & 4,03 & 0,47 & 0,694 & 8,207 \\
\hline PERCE.3 - Normalmente dedico tiempo a pensar en mis emociones. & 3,73 & 0,53 & 0,714 & 7,004 \\
\hline PERCE.4 - Merece la pena prestar atención a mis emociones y ánimo. & 4,27 & 0,50 & 0,650 & 6,645 \\
\hline PERCE.5 - Dejo que mis sentimientos afecten a mis pensamientos. & 3,52 & 0,42 & \multicolumn{2}{|c|}{ Suprimido } \\
\hline PERCE.6 - Pienso en mi estado de ánimo constantemente. & 3,37 & 0,52 & \multicolumn{2}{|c|}{ Suprimido } \\
\hline PERCE.7 - A menudo pienso en mis sentimientos. & 3,66 & 0,44 & 0,783 & 7,467 \\
\hline PERCE.8 - Presto mucha atención a cómo me siento. & 3,83 & 0,45 & 0,746 & 7,441 \\
\hline Comprensión: $\lambda=0,679 ;$ Sig. $=4,724(\alpha=0,857 ; F C=0,86 ; \mathrm{VE}=0,56)$ & $\mathrm{x}$ & $\mathrm{S}^{2}$ & $\lambda$ & Sig. \\
\hline COMPR.1 - Tengo claros mis sentimientos. & 3,93 & 0,46 & 0,755 & Fijado \\
\hline COMPR.2 - Puedo definir mis sentimientos con normalidad. & 3,88 & 0,50 & 0,840 & 10,079 \\
\hline COMPR.3 - Casi siempre sé cómo me siento. & 3,87 & 0,43 & 0,686 & 8,618 \\
\hline COMPR.4 - Suelo conocer mis sentimientos sobre las otras personas. & 4,12 & 0,49 & \multicolumn{2}{|c|}{ Suprimido } \\
\hline COMPR.5 - Me doy cuenta de mis sentimientos en situaciones diversas. & 4,00 & 0,38 & \multicolumn{2}{|c|}{ Suprimido } \\
\hline COMPR.6 - Siempre puedo decir cómo me siento. & 3,57 & 0,51 & 0,721 & 8,569 \\
\hline COMPR.7 - Soy capaz de decir cuáles son mis emociones con facilidad. & 3,79 & 0,44 & 0,728 & 7,303 \\
\hline COMPR.8 - Puedo llegar a comprender mis sentimientos. & 3,94 & 0,51 & \multicolumn{2}{|c|}{ Suprimido } \\
\hline Regulación: $\lambda=0,758 ;$ Sig. $=5,375(\alpha=0,826 ; F C=0,83 ; \mathrm{VE}=0,50)$ & $\mathrm{x}$ & $S^{2}$ & $\lambda$ & Sig. \\
\hline REGUL.1 - Aunque me sienta triste, suelo tener una visión optimista. & 3,86 & 0,54 & 0,728 & Fijado \\
\hline REGUL.2 - Aunque me sienta mal, procuro pensar en cosas agradables. & 3,96 & 0,54 & 0,808 & 9,765 \\
\hline REGUL.3 - Cuando estoy triste, pienso en todos los placeres de la vida. & 3,52 & 0,64 & 0,704 & 8,275 \\
\hline REGUL.4 - Intento tener pensamientos positivos aunque me sienta mal. & 3,85 & 0,51 & 0,667 & 6,448 \\
\hline REGUL.5 - Si doy demasiadas vueltas a las cosas, trato de calmarme. & 3,93 & 0,64 & \multicolumn{2}{|c|}{ Suprimido } \\
\hline REGUL.6 - Me preocupo por tener un buen estado de ánimo. & 4,11 & 0,54 & 0,607 & 6,990 \\
\hline REGUL.7 - Tengo mucha energía cuando me siento feliz. & 4,57 & 0,38 & \multicolumn{2}{|c|}{ Suprimido } \\
\hline REGUL.8 - Cuando estoy enfadado intento cambiar mi estado de ánimo. & 3,73 & 0,53 & \multicolumn{2}{|c|}{ Suprimido } \\
\hline \multicolumn{5}{|c|}{ Satisfacción en el Proceso de Aprendizaje Cooperativo del Estudiante ( $F C=0,95 ; \mathrm{VE}=0,72)$} \\
\hline Toma de decisiones: $\lambda=0,865 ;$ Sig. $=10,905(\alpha=0,738 ; \mathrm{FC}=0,87 ; \mathrm{VE}=0,77)$ & $\mathrm{x}$ & $\mathrm{S}^{2}$ & $\lambda$ & Sig. \\
\hline DECIS.1 - Se han establecido normas internas para facilitar el trabajo en equipo. & 3,52 & 0,69 & \multicolumn{2}{|c|}{ Suprimido } \\
\hline DECIS.2 - Todos los miembros han participado en las tareas del equipo. & 3,93 & 0,93 & 0,823 & Fijado \\
\hline DECIS.3 - Las decisiones se han tomado teniendo en cuenta la opinión de todos. & 4,15 & 0,64 & 0,926 & 10,603 \\
\hline Gestión de conflictos: $\lambda=0,988 ;$ Sig. $=8,717(\alpha=0,700 ; F C=0,70 ;$ VE=0,52) & $\mathrm{x}$ & $S^{2}$ & $\lambda$ & Sig. \\
\hline CONFL.1 - Las discrepancias han permitido considerar nuevos puntos de vista. & 3,98 & 0,55 & 0,713 & Fijado \\
\hline CONFL.2 - Si ha habido conflictos se han resuelto sin perjuicio de nadie. & 4,31 & 0,66 & 0,732 & 7,808 \\
\hline Resolución de problemas: $\lambda=0,770 ;$ Sig. $=6,344(\alpha=0,706 ; F C=0,70 ; \mathrm{VE}=0,54)$ & $\mathrm{x}$ & $s^{2}$ & $\lambda$ & Sig. \\
\hline RESOL.1 - Se ha seguido algún tipo de método para la resolución de los casos. & 3,76 & 0,67 & 0,680 & Fijado \\
\hline RESOL.2 - Se ha potenciado la creatividad para la resolución de los problemas. & 3,91 & 0,67 & 0,783 & 6,328 \\
\hline Colaboración: $\lambda=0,975 ;$ Sig. $=8,557(\alpha=0,810 ; F C=0,81 ; \mathrm{VE}=0,59)$ & $\mathrm{x}$ & $S^{2}$ & $\lambda$ & Sig. \\
\hline COLAB.1 - Las tareas de cada uno han estado claras en contenido y en plazo. & 3,93 & 0,70 & 0,651 & Fijado \\
\hline COLAB.2 - Tus compañeros han contribuido al equipo tal y como se estableció. & 3,96 & 0,74 & 0,762 & 7,952 \\
\hline COLAB.3 - Ha existido colaboración entre los miembros. & 4,12 & 0,69 & 0,883 & 7,975 \\
\hline Liderazgo: $\lambda=0,658 ;$ Sig. $=6,715(\alpha=0,874 ; F C=0,88 ; \mathrm{VE}=0,78)$ & $\mathrm{x}$ & $\mathrm{S}^{2}$ & $\lambda$ & Sig. \\
\hline LIDER.1 - El líder del equipo ha sido aceptado por todos los miembros. & 3,92 & 0,64 & 0,926 & Fijado \\
\hline LIDER.2 - El líder del equipo ha dirigido y coordinado las actividades del equipo. & 3,89 & 0,58 & 0,838 & 9,145 \\
\hline Confianza: $\lambda=0,933$; Sig. $=12,226(\alpha=0,860 ; \mathrm{FC}=0,87 ; \mathrm{VE}=0,70)$ & $\mathrm{x}$ & $S^{2}$ & $\lambda$ & Sig. \\
\hline
\end{tabular}




\begin{tabular}{|l|c|c|c|c|}
\hline CONFI.1 - El trabajo del equipo ha transcurrido en un ambiente de confianza. & 4,17 & 0,71 & 0,891 & Fijado \\
\hline CONFI.2 - A pesar de las diferencias, ha existido un ambiente de respeto. & 4,51 & 0,47 & 0,705 & 8,068 \\
\hline CONFI.3 - La comunicación interna ha sido buena entre los miembros. & 4,22 & 0,64 & 0,892 & 13,670 \\
\hline Retroalimentación: $\lambda=0,700 ;$ Sig. $=7,111$ ( $\alpha=0,894 ; \mathrm{FC}=0,89 ; \mathrm{VE}=0,59)$ & $\mathrm{X}$ & $\mathrm{S}^{2}$ & $\lambda$ & Sig. \\
\hline RETRO.1 - Los objetivos se han transmitido bien y han sido comprendidos. & 4,22 & 0,49 & 0,821 & Fijado \\
\hline RETRO.2 - El profesor ha facilitado los recursos que el equipo ha necesitado. & 4,33 & 0,56 & 0,740 & 11,326 \\
\hline RETRO.3 - Las actividades a realizar han estado claras en contenido y en plazo. & 4,17 & 0,54 & 0,816 & 11,708 \\
\hline RETRO.4 - Los criterios de evaluación se han transmitido y se han comprendido. & 4,10 & 0,51 & 0,844 & 12,930 \\
\hline RETRO.5 - Hemos tenido acceso a la información que hemos necesitado. & 4,34 & 0,46 & 0,733 & 8,116 \\
\hline RETRO.6 - El equipo ha podido comunicarse fácilmente con los profesores. & 4,54 & 0,37 & 0,614 & 7,643 \\
\hline RETRO.7 - Hemos recibido información acerca del resultado de nuestro trabajo. & 4,07 & 0,65 & Suprimido \\
\hline RETRO.8 - El trabajo ha sido valorado públicamente al resto de la clase. & 3,90 & 0,82 & Suprimido \\
\hline X2=26,347, gl=19, p=0,121; NFI=0,956; NNFI=0,964; IFI=0,985; CFI=0,985; GFI=0,956; RMR=0,047; RMSEA=0,064 \\
\hline
\end{tabular}

Por último, se analizó la validez convergente y discriminante. En referencia a la primera, bastó con observar que el valor estimado de las correlaciones entre las dimensiones que configuran las escalas era elevado y significativo. Por su parte, la validez discriminante de los constructos se muestra en la Tabla 2, evaluada a través de la VE. Así, cuando la raíz cuadrada de la VE entre cada par de factores es mayor que la correlación estimada entre tales factores, como es el caso, la validez discriminante queda ratificada (Fornell and Larcker, 1981). Llegados a este punto, podemos decir que el modelo de medida planteado es fiable y válido para su utilización empírica en el trabajo de campo llevado a cabo.

Tabla 2: Validez discriminante de las escalas de medición. (Nota: por debajo de la diagonal se muestra la correlación estimada entre los factores; la diagonal recoge la raíz cuadrada de la VE; ${ }^{* \star} \mathrm{p}<.01$ )

\begin{tabular}{|l|l|c|}
\hline & IE & SAT \\
\hline Inteligencia emocional (IE) & 0,72 & \\
\hline Satisfacción en el proceso de aprendizaje cooperativo (SAT) & $0,53^{* *}$ & 0,84 \\
\hline
\end{tabular}

\section{RESULTADOS}

Con el fin de evaluar el nivel de IE de los estudiantes una vez implementadas las distintas fases que componen esta experiencia docente se suministra el TMMS-24 al alumnado a la finalización del curso. La Tabla 3 resume los valores promedios obtenidos en el trabajo de campo. Como puede observarse, se obtienen valores homogéneos próximos a 4 en las tres dimensiones que componen la IE del estudiante (3,94 en percepción de las emociones, 3,81 en comprensión emocional y 3,86 en regulación de las emociones), siendo el grado de IE global de 3,87.

Tabla 3: Valores promedio sobre la escala de medición de la inteligencia emocional del estudiante (Nota: donde $\mathrm{x}$ recoge el valor promedio y $S^{2}$ la varianza del factor)

\begin{tabular}{|l|c|c|}
\hline Factor & $\mathrm{x}$ & $\mathrm{S}^{2}$ \\
\hline Percepción (PERCE) & 3,94 & 0,28 \\
\hline Comprensión (COMPR) & 3,81 & 0,29 \\
\hline Regulación (REGUL) & 3,86 & 0,33 \\
\hline Inteligencia emocional & 3,87 & 0,18 \\
\hline
\end{tabular}

Simultáneamente se evalúa el grado de satisfacción de cada estudiante en su proceso de AC mediante el Viles et al. (2013). Tal y como se muestra en la Tabla 4, en términos medios se consigue un nivel de satisfacción elevado $(4,07)$ que se mantiene en cada una de las dimensiones que componen el constructo principal (4,04 en cuanto a la participación en la toma de decisiones, 4,14 en la gestión de conflictos, 3,83 en la resolución de problemas, 4,00 en la colaboración, 3,91 en el liderazgo, 4,30 en la confianza y 4,28 en la retroalimentación). Entrando en detalle, la mayor satisfacción del estudiante en su proceso de AC asociado a la experiencia docente implementada se da en términos de la confianza generada entre los miembros del equipo $(4,30)$, así como en la retroalimentación establecida entre alumno y profesorado $(4,28)$. Por su parte, y aún manteniendo valores elevados cercanos a 4 , la resolución de problemas $(3,83)$ y el liderazgo $(3,91)$ son los únicos aspectos con valoraciones por debajo de esta cifra. 
Tabla 4: Valores promedio sobre la escala de medición de la satisfacción en el aprendizaje cooperativo del estudiante (Nota: donde $\mathrm{x}$ recoge el valor promedio y $\mathrm{S}^{2}$ la varianza del factor)

\begin{tabular}{|l|c|c|}
\hline Factor & $\mathrm{x}$ & $\mathrm{S}^{2}$ \\
\hline Toma de decisiones (DECIS) & 4,04 & 0,62 \\
\hline Gestión de conflictos (CONFL) & 4,14 & 0,42 \\
\hline Resolución de problemas (PROBL) & 3,83 & 0,49 \\
\hline Colaboración (COLAB) & 4,00 & 0,51 \\
\hline Liderazgo (LIDER) & 3,91 & 0,54 \\
\hline Confianza (CONFI) & 4,30 & 0,47 \\
\hline Retroalimentación (RETRO) & 4,28 & 0,31 \\
\hline Satisfacción en el aprendizaje cooperativo & 4,07 & 0,30 \\
\hline
\end{tabular}

De forma adicional, tratamos de determinar en qué medida aquellos estudiantes con niveles más altos en las competencias asociadas a la IE son los que presentan un mayor grado de satisfacción en su proceso de AC. Para ello utilizamos el programa estadístico IBM SPSS Statistics 22. En primer lugar se comprueba, a través del test de Kolmogorov-Smirnov, que en todos los casos se rechaza la hipótesis nula de que las variables analizadas siguen una distribución normal. Así, al presentar significatividades por debajo de 0,05 asumimos la ditribución anormal de los datos. En base a ello, se lleva a cabo un análisis de correlación a través del estudio del coeficiente de Spearman. Esta prueba no paramétrica se utiliza como alternativa al coeficiente de Pearson cuando no se puede suponer la normalidad de la muestra, como es el caso.

A la luz de los resultados obtenidos que se muestran en la Tabla 5, se observa que prácticamente en la totalidad de los casos se rechaza la hipótesis nula, demostrando así la existencia de una correlación positiva y significativa entre las dimensiones que componen la IE del estudiante respecto a las dimensiones que determinan su satisfacción en su proceso de AC.

Tabla 5: Resultados de los análisis de correlación de Spearman entre la satisfacción en el aprendizaje cooperativo del estudiante respecto a su grado de inteligencia emocional (Nota: ${ }^{*} p<0,05 ;{ }^{* *} p<0,01$ )

\begin{tabular}{|c|c|c|c|c|c|c|c|c|}
\hline \multicolumn{2}{|c|}{} & DECIS & CONFL & PROBL & COLAB & LIDER & CONFI & RETRO \\
\hline \multirow{2}{*}{ PERCE } & Coef. & $0,206^{*}$ & $0,309^{* *}$ & $0,305^{* *}$ & $0,223^{*}$ & 0,148 & $0,185^{*}$ & $0,475^{* *}$ \\
\cline { 2 - 9 } & Sig. & 0,023 & 0,001 & 0,001 & 0,014 & 0,105 & 0,042 & 0,000 \\
\hline \multirow{2}{*}{ COMPR } & Coef. & $0,283^{* *}$ & $0,254^{* *}$ & $0,295^{* *}$ & $0,202^{*}$ & $0,241^{* *}$ & $0,211^{*}$ & $0,227^{*}$ \\
\cline { 2 - 9 } & Sig. & 0,002 & 0,003 & 0,001 & 0,026 & 0,008 & 0,020 & 0,012 \\
\hline \multirow{2}{*}{ REGUL } & Coef. & $0,336^{* *}$ & $0,217^{*}$ & $0,261^{* *}$ & $0,309^{* *}$ & $0,277^{* *}$ & $0,237^{* *}$ & $0,334^{* *}$ \\
\cline { 2 - 9 } & Sig. & 0,000 & 0,017 & 0,004 & 0,001 & 0,002 & 0,009 & 0,000 \\
\hline
\end{tabular}

Estos resultados dan muestra de la importancia de tratar de potenciar cada una de las dimensiones de la IE en los estudiantes pues éstas contribuirán a un proceso de aprendizaje grupal mucho más satisfactorio. En este sentido, la experiencia docente basada en la implementación programada de actividades y acciones como las que se detallan en el presente trabajo puede resultar de suma utilidad.

\section{CONCLUSIONES}

Las exigencias del mundo actual vienen marcadas por la creciente búsqueda del desarrollo del potencial humano en los diferentes ámbitos sociales y profesionales. El funcionamiento de cualquier grupo en el que se vea inmerso el sujeto a lo largo de su trayectoria vital requiere el desarrollo de habilidades socioemocionales que le permitan cooperar para lograr la interacción efectiva entre pares. Los alumnos deben, en el aula y en la vida, no sólo de ser capaces de desplegar capacidades relativas a la toma de decisiones sino de valorar las consecuencias de dichas decisiones, tanto para sí mismos como para los otros, anteponiendo el interés general al individual. Únicamente de esta forma el sujeto será capaz de generar confianza en el grupo con el que se trabaja, comunicar con eficacia, gestionar conflictos derivados del trato personal, aprender a mediar en conflictos de terceros, resolver problemas, etc.

El competitivo mercado laboral está demandando a profesionales que no sólo tengan una gran capacitación técnica, sino que tengan la capacidad de adaptarse a los cambios, que sean permeables y flexibles, capaces de liderar personas y por tanto gestionar emociones. El sistema universitario, como generador de 
factores de socialización, debe incorporar dentro del currículum formativo de cada especialidad metas que obliguen a los docentes a formar a los alumnos en el desarrollo de sus habilidades socio-emocionales. El objetivo es formar titulados universitarios, capaces de enfrentarse a los retos del mercado laboral de una forma emocionalmente saludable.

En esta línea y en el contexto de la asignatura Técnicas de Ventas, este trabajo aboga por la necesidad de formar a los futuros vendedores no sólo en las competencias específicas de la asignatura sino también en las habilidades socio-emocionales. El desarrollo profesional de la venta se ejercita inmerso en estructuras organizativas en las que el vendedor debe aprender a relacionarse con el staff organizativo a la vez que con los clientes. Esto, en ocasiones, le puede poner en situaciones emocionalmente comprometidas (reclamaciones, pérdida de clientes, cierres de venta fallidos...) en los que se puede generar un conflicto de intereses que pondrá a prueba sus habilidades socio-emocionales, su IE. En este sentido, proponemos desarrollar el AC como metodología de entrenamiento de la IE. La utilización de métodos de enseñanzaaprendizaje que involucren tanto el aprendizaje explícito (clase magistral, discusiones grupales, lecturas, debates, etc.) como el aprendizaje implícito (proyectos, juegos, experiencias, dinámicas, etc.) pueden ser tremendamente útiles para este fin.

De lo expuesto y analizado en este trabajo, se pueden obtener las siguientes conclusiones principales:

1) El contexto social y económico actual demanda profesionales dotados de habilidades socioemocionales. Este trabajo propone una experiencia docente consistente en un conjunto de actividades temporalizadas hasta en un total de cinco fases que puede servir de referencia para el entrenamiento de tales habilidades en el contexto de la formación en ventas.

2) La experiencia propuesta plantea un clima de aprendizaje satisfactorio para el estudiante basado en la aplicación de la IE en un contexto de enseñanza cooperativo. Así, los resultados obtenidos muestran, en términos medios, un nivel de satisfacción elevado por parte de los estudiantes respecto al proceso de aprendizaje seguido en la asignatura.

3) De forma más específica, los aspectos asociados al proceso de AC llevado a cabo que más positivamente han sido valorados por los estudiantes se corresponden con las actividades cooperativas ligadas a la comunicación del grupo, tanto en términos internos (confianza entre los miembros), como externos (retroalimentación entre el grupo y el profesorado). Por su parte, los alumnos presentan valoraciones por debajo del resto de habilidades consideradas en relación a aquellas ligadas a la resolución de problemas y al liderazgo interno.

4) El conjunto de actividades implementadas a lo largo del curso contribuyen a la formación de ciertas competencias transversales de ámbito socio-emocional. A la luz de los resultados obtenidos tras finalizar la experiencia docente los estudiantes presentan valores promedios elevados en cada una de las habilidades que componen el constructo IE: percepción, comprensión y regulación emocional. Más aún, las valoraciones obtenidas sobre cada una de estas dimensiones presenta un peso relativo equilibrado entre sí.

5) En base al análisis conjunto de los constructos de la experiencia docente (IE del estudiante y grado de satisfacción con su $A C$ ) encontramos una relación positiva y significativa entre el desarrollo y potenciación de las habilidades socio-emocionales del estudiante y su nivel de satisfacción en el marco de un AC.

6) Con todo, concluimos que el desarrollo de la experiencia docente expuesta, consigue despertar la curiosidad del estudiante sobre la IE y la importancia de las emociones para la práctica profesional de la venta, todo ello bajo un contexto de AC programado que se centra la labor de equipo puesta en práctica por los estudiantes.

\section{REFERENCIAS}

ANECA, Libro blanco de grado en Pedagogía y Educación Social, (en la web: http://www.aneca.es/var/media/150392/libro blanco_pedagogía1_0305.pdf., acceso: 28 de Mayo de 2016), Agencia Nacional de Educación de la Calidad y Acreditación-ANĒCA, Madrid, España (2005)

André, A., Louvet, B y Deneuve, P. C., Cooperative group, risk-talking and inclusión of pupíls with learning disabilities in physical education, British Educational Research Journal, 39 (4), 677-693 (2013)

Bagozzi, R. P. y Youjae, Y, On the Evaluation of Structural Equation Models, Journal of the Academy of Marketing Science, 16(Spring), 74-94 (1988) 
Barnett, L., Echeita, G., y otros 15 autores, Motivación, tratamiento de la diversidad y rendimiento académico: El aprendizaje cooperativo. Editorial Graó, Barcelona, España (2003)

Bisquerra, R., Educación emocional y competencias básicas para la vida, Revista de Investigación Educativa, 21(1), 7-43 (2003)

Bono, E., Six Thinking Hats: An essential approach to business management. Little, Brown, \& Company, New York, USA (1985)

Brackett, M.A., Patti, J., Stern, R., Rivers, S.E., Katulak, N.A., Crisholm, C. y Salovey, P., A sustainable, skill-based approach to building emotionally literate schools. En M. HUGHES, J. TERRELL y R.THOMPSON (Eds.), The handbook of developing emotional and social intelligence: Best practices, cases studies, and tools. Wiley Pfeiffer, New York, USA (2008)

Castro, P.J. y González-Palta, I.N., Percepción de Estudiantes de Psicología sobre el uso de Facebook para desarrollar pensamiento crítico, Formación Universitaria, 9(1), 45-55 (2016)

Darnis, F. y Lafont, L., Cooperative learning and dyadic interactions: Two modes of knowledge construction in socio-constructivist setting for team-sport teaching, Physical Education and Sport Pedagogy, iFirst Article (2013)

Delors, J., La educación encierra un tesoro. Informe a la UNESCO de la Comisión Internacional sobre la Educación para el siglo XXI, (en la web: http://www.unesco.org/delors/delors.pdf., acceso: 3 de Abril de 2016), Santillana-Unesco, Madrid, España (1996)

Domingo, J., El aprendizaje cooperativo, Cuadernos de Trabajo Social, 21, 231-246 (2008)

Doucet, L., Wang, B.S.L., Oldham, G.R., I know how you feel, but it does not always help: Integrating emotion recognition, agreeableness, and cognitive ability in a compensatory model of service performance, Journal of Service Management, 27 (3), 1-36 ( 2016)

Druskat, V.U. y Wheeler, J.V., Managing from the boundary: The effective leadership of self-managing work teams, Academy of Management Journal, 46 (4), 435-57 (2003)

Durlak, J. A., Weissberg, R. P., y otros tres autores, The impact of enhancing students' social and emotional learning: A meta-analysis of school-based universal interventions, Child Development, 82(1), 405-432 (2011)

Extremera, N., Durán, A. y Rey, L., Inteligencia emocional y su relación con los niveles de burnout, engagement y estrés en estudiantes universitarios, Revista Educación, 341, 239-256 (2007)

Fernández-Berrocal, P. y Ramos, N., Desarrolla tu inteligencia emocional. Kairós, Barcelona, España (2004)

Fernández-Berrocal, P. y Ruiz-Aranda, D., La educación de la inteligencia emocional desde el modelo Mayer y Salovey. En A.COSTA, Educación emocional y convivencia en el aula. Ministerio de Educación y Ciencia. Madrid, España (2008)

Fernández-Rio, J. y Méndez-Giménez, A., El aprendizaje cooperativo: Modelo pedagógico para educación física, Retos, 29, 201-206 (2016)

Ferreiro, R., Una visión de conjunto a una de las alternativas educativas más impactantes de los últimos años: El aprendizaje cooperativo, Revista Electrónica de Investigación Educativa, 9 (2), 1-9 (2007)

Filella, G., Pérez, N., Morera, M. J. A., y Granado, X. O., Resultados de la aplicación de un programa de educación emocional en Educación Primaria, Estudios Sobre Educación, 26, 125-147 (2014)

Fornell, C. y Larcker, D.F., Evaluating structural equation models with unobservable variables and measurement error, Journal of Marketing Research, 18, pp. $39-50$ (1981)

Garaigordobil, M. y Oñederra, J.A., Inteligencia emocional en las víctimas de acoso escolar y en los agresores, European Journal of Education and Psychology, 3 (2), 243-256 (2010)

Geoffroy, E., Origen y característica del Sistema de aseguramiento de la calidad de la educación superior chileno (en la web: http://dx.doi.org/10.6018/reifop.17.3.204051., acceso 5 de Mayo de 2016), Revista Electrónica Interuniversitaria de Formación del Profesorado, 17(3), 49-64 (2014) 
Goleman, D., Emotional intelligence (en la web: http://www.aneca.es/var/media/150392/libro blanco_pedagogía1_0305.pdf., acceso: 28 de Mayo de 2016), Batam Books, New York, USA (1995)

Goleman, D., Working with emotional intelligence. Batam Books, New York, USA (1998)

Goleman, D., Leadership that gets results, Harvard Business Review, 78 (2), 80-90 (2000)

Goleman, D., Boyatzis, R. y McKee, A., Primal leadership: Realizing the power of emotional intelligence. Harvard Business School, Boston, USA (2002)

González-Arias, M.I. y Alucema, L.B. Formación universitaria en carreras de ingeniería y pedagogía. Revisitando un antiguo debate, Formación Universitaria, 8(6), 13-22 (2015)

Gravity. El filósofo. Obtenido de Conectivismo: Teoria del aprendizaje (en la web: http://elfilosofo.wordpress.com//2013/03/15/conectivismo-teoria-del-aprendizaje., acceso: 15 de Marzo de 2013, Aplicaciones de Filosofía, Madrid, España (2013)

Hair, J.F., Black, W.C., Babin, B.J. y Anderson, R.E., Multivariate Data Analysis, Prentice Hall, Upper Saddle River, NJ (2009)

Hernández, M.R., Rodríguez, V. M., Parra, F.J. y Velázquez, P., Las tecnologías de la información y la comunicación (TICs) en la enseñanza-aprendizaje de la química orgáncia a través de imágenes, juegos y videos, Formación Universitaria, 10 (7), 31-40 (2014)

Herrmann, S.L.M., The creative brain evolution. Brain Books, Búfalo, USA (1989)

Jöreskog, K. y Söbom, D., LISREL 8: structural equation modeling with the SIMPLIS command language, Scientific Software International, Chicago, Illinois (1993)

Jiménez, C.A. Diagnóstico teoría del cerebro total. Magisterio, Perieda, Colombia (2006)

Kagan, S., Cooperative learning resources for teachers. Resources for Teachers, C.A., San Juan Capistrano, USA (1992)

Kamp, R.J.A., Dolmans, D.M.J.M., Van Berkel, H.J.M. y Schmidt, H.G. The relationship between students' small group activities, time spent on self-study, and achievement, Higher Education, 64, 385-397 (2012)

Klare, D., Behney, M. y Ferrer, B., Emotional intelligence in a stupid world, Library Hi Tech News, 31 (6), 21 24 (2014)

Li, Z., Gupta, B., Loon, M. y Casimir, G., Combinative aspects of leadership style and emotional intelligence, Leadership \& Organization Development Journal, 37 (1), 107-125(2016)

Martí-Vilar, M., Cortés, J. P., Noguera, J. J., \& Company, I. D., Conectivismo: Propuesta de las NTIC para la docencia: (en la web: http://www.academia.edu/3182163/Conectivismo_Propuesta_de_las_NTIC_para_la_docencia, acceso: 6 de Marzo de 2013), Academia (2013)

Mayer, J.D. y Salovey, P., What is emotional intelligence?. En P. Salovey y D. Sluyter. Emotional development and emotional intelligence: Implications for educators. Basic Books, New York, USA (1997)

Mayer, J.D., Salovey, P. y Caruso, D., Emotional intelligence test (MSCEIT) users manual. MHS, Toronto, Canada (2002)

Miranda, A., Santos, G. y Stipcich, S., Algunas características de investigaciones que estudian la integración de las TIC en la clase de ciencia, Revista Electrónica de Investigación Educativa, 12(2), 1-24 (2008)

Momm, T., Blickle, G., Liu, Y., Wihler, A., Kholin, M. y Menges, J. I., It pays to have an eye for emotions: Emotion recognition ability indirectly predicts annual income, Journal of Organizational Behavior, 36 (1), 147-163 (2015)

Monferrer, D., Estrada, M., Fandos, J.C., Callarisa, LL., Tena, S., Dirección de ventas. Una versión integral. Pirámide, Barcelona, España (2014)

Nunnally, J., Psychometric Theory, McGraw-Hill, Nueva York (1979) 
Osuna, C. y Luna, E., Características de ser un buen profesional de ingeniería en la Universidad Autónoma de Baja California, México, Formación Universitaria, 1 (1), 29-36 (2008)

Ovalles, L. C., Conectivismo, ¿un nuevo paradigma en la educación actual?, Revista MundoFesc, 1(7), $72-$ 79 (2014)

Ovejero, A., El aprendizaje cooperativo. Una alternativa eficaz a la enseñanza tradicional. PPU, Barcelona, España (1990)

Pérez-Serrano, M., Rol docente y pedagogía activa en la formación universitaria. La enseñanza centrada en el aprendizaje del alumno. Adaptación del programa al EEES, Humanismo y Trabajo Social, 4, 153-175 (2006)

Pérez, P. R. A., Afonso, M. C. G. y Aguilar, D. L., La enseñanza universitaria y la formación para el trabajo. Un análisis desde la opinión de los estudiantes, Paradigma, 30(2), 7-19 (2015)

Riesco, M., El enfoque por competencias en el EEES y sus implicaciones en la enseñanza aprendizaje, Tendencias Pedagógicas, 13,79-105 (2015)

Rosa, G., Navarro-Segura, L. y López, P., El aprendizaje de las habilidades sociales en la Universidad. Análisis de una experiencia formativa en los grados de educación social y trabajo social, Formación Universitaria, 7(4), 25-38 (2014)

Rosa, G., Riberas, G., Navarro-Segura, L. y Vilar, J., El coaching como herramienta de trabajo de la competencia emocional en la formación de estudiantes de educación social y trabajo social de la Universidad Ramón Llull, España, Formación Universitaria, 8(5), 77-90 (2015)

Salovey, P. y Mayer, J. D., Emotional intelligence, Imagination, Cognition and Personality, 9(3), 185-211 (1990)

Salovey, P., Mayer, J.D., y otros tres autores, Emotional attention, clarity, and repair: Exploring emotional intelligence using the Trait Meta-Mood Scale. En J.W. PENNEBAKER (Ed.). Emotion, disclousure and health. American Psychologucal Association, Washington, USA (1995)

Schumacher, L., Wheeler, J.V. y Carr, A.S., The relationship between emotional intelligence and buyer's performance, Journal of Business \& Industrial Marketing, 24 (3/4) 269 - 277 (2009)

Segarra, M., Estrada, M., Monferrer, D., Estilos de aprendizaje en estudiantes universitarios: laterización vs. interconexión de los hemisferios cerebrales, Revista Española de Pedagogía, 262, 583-600 (2015)

Siemens, G. Connectivism: A Learning Theory for the Digital Age (en la web: http://citeseerx.ist.psu.edu/viewdoc/ad?doi=10.1.1.87.3793\&rep=rep1\&type=pdf, acceso 5 de Mayo de 2016), (2004)

Siemens, G., Teoría del conectivismo (en la web: http://www. elearnspace. org., acceso 5 de Mayo de 2016), (2008)

Skillman, P., TED Talk video of Tom Wujec explaining the Marshmallow Challenge. (en la web: http://marshmallowchallenge.com/TED_Talk.html., acceso 19 de Enero de 2016) (2016)

Sims, R., Promises of interactivity: Aligning learner perceptions and expectations with strategies for flexible and online learning, Distance Education, 24(1), 87-103 (2003)

Slavin, R.E., Cooperative learning and academic achievement: Why does groupwork work?, Anales de Psicología, 30 (3), 785-791 (2014)

Steenkamp, J.B.E.M. y van Trijp, H.C.M., The use of lisrel in validating marketing constructs, International Journal of Reesearch in Marketing, 8 (4), 283-299 (1991)

Torras, Ma․ E., El aprendizaje colaborativo en línea y la ética del ciudadano, Estudios sobre Educación, 24, 149-171 (2013) 
Traver, J.A., Aprendizaje cooperativo y educación intercultural. En A. Sales (coord.), Educació Intercultural: La diversitat cultural a l'escola. Castelló: Uji Col.lecció, Servei de Publicacions Universitat Jaume I, Universitat Jaume I, Castellón, España (2003)

Vallet, T., Rivera, P. y Vallet, I. y Vallet, A., Eficacia del plan de marketing como técnica de aprendizaje cooperativo, European Research on Management and Business Economics, 22(1), 17-24 (2016)

Viles, E., Zárraga-Rodríguez, M. y Jaca, C., Herramienta para evaluar el funcionamiento de los equipos de trabajo en entornos docentes, Intangible Capital, 9 (1), 281-304 (2013)

Walters, L., Four leading models (en la web: http://www.edletter.org/past/issues/2000-mj/models.shtml., acceso 19 de Enero (2016). Harvard Education Letters' Research Online, 1992 (2000)

Zapata-Ros, M., Teorías y modelos sobre el aprendizaje en entornos conectados y ubicuos: Bases para un nuevo modelo teórico a partir de una visión crítica del "conectivismo", Teoría de la Educación; Educación y Cultura en la Sociedad de la Información, 16(1), 69 (2015) 
